\title{
Relationship of the upright agonistic posture in the foot shock situation to dominance-submission in male C57BL/6 mice'
}

\section{G. MCA. KIMBRELL, ${ }^{2}$ The University of Tennessee, Knoxville, Tenn. 37916}

The agonistic behavior of male C57BL/6 mice was observed in shock and nonshock round-robins. It was found that there was a positive relationship between dominance rank of the participants and frequency of upright reactions in the foot-shock situation. These results suggested that the upright reaction observed in the foot-shock situation be identified not as an attack behavior as is typically done, but rather as an ambivalent, threat, or defense behavior.

The purpose of this study was to determine the relationship between dominance-submission and the frequency of the upright agonistic posture produced in a foot-shock situation similar to that employed by Ulrich \& Azrin (1962). This study was part of an extensive series of experiments on the usefulness of the foot-shock technique for the study of agonistic behavior in various strains of mice. Among numerous agonistic behavior patterns, the upright posture is of particular interest not only because of its ease of induction in a foot-shock situation, reliability of measurement, and known relationship to various parameters such as shock intensity, rate, floor area, etc. in rats (Ulrich, 1966), but also because of some amount of controversy over its classification (King, 1966; Scott, 1966). As further evidence, if not of controversy, at least of lack of clarity or precision as to its proper classification, the upright posture in mice has been defined as an index of submission or submissiveness (Beeman, 1947; Clark \& Schein, 1966; Ginsburg \& Allee, 1942; Scott \& Fredericson, 1951; VanAbeelen, 1966; Warne, 1947), as fighting (Tedeschi, Tedeschi, Mucha, Cook, Mattis, \& Fellows, 1959), and as defensiveness (Bauer, 1956; Kahn, 1951, 1954; Scott, 1946, 1947, 1966; Scott \& Fredericson, 1951; Scott \& Marston, 1953).

When observed in rats in the foot-shock situation it has most often been defined as an attack or fighting response (Ulrich, 1966; Ulrich \& Azrin, 1962). While important species differences do exist, the similarity of agonistic behavior in mice and rats has been frequently stressed (Scott, 1966). There is a certain danger in assuming that even topographically similar patterns are functionally equivalent in different species (Kimbrell, 1968). In an extensive series of observations, Grant \& McKintosh (1963) have shown that the upright posture in mice and in rats seems to be equivalent not only in topography but in function and in controlling relationships. They classified the upright posture as ambivalent, meaning that it was under the control of simultaneously produced but incompatible flight and attack "tendencies" or "drives." It might be pointed out that postures and behaviors of this variety are usually referred to as threat behaviors by ethologists.

The present study was intended to determine the relationship of the upright posture observed in foot shock situations to dominance-submission and from this hopefully to formulate a clearer notion of the "meaning" or identity of the upright posture as an element of agonistic behavior when produced by foot shock.

$$
\text { METHOD }
$$

The Ss were five male C57BL/6 Cum mice housed in isolation from age 44 days throughout the experiment. Age at beginning of the shock round-robin was 94 days, and at the nonshock round-robin, 149 days.

All observations were made while the mice were paired in a grid box (stainless steel rods $4 \mathrm{~mm}$ diam, spaced $1 \mathrm{~cm}$ center-tocenter) and covered by an inverted $1,000-\mathrm{ml}$ glass beaker ( $10.5 \mathrm{~cm}$ diam $\times 13.5 \mathrm{~cm}$ high). Shock $(.8 \mathrm{~mA})$ was supplied by an Applegate 228 constant-current dc stimulator delivered to the grid through a Grason-Stadler E1064GSP polarity scrambler. A recycling timer network (two Hunter 111-C) controlled shock duration $(.2 \mathrm{sec})$ and rate $(30 / \mathrm{min})$. Behavioral events were recorded on a Gerbrands event recorder.

Mice were handled by the tail with padded forceps, and the grid box was wiped clean between bouts. Each mouse participated in only one bout per day.

In the shock round-robin, each mouse was paired once with each of his four opponents. A bout consisted of placing a pair of mice under the beaker. After an observation period of $5 \mathrm{~min}, 3 \mathrm{~min}$ of shocks were delivered. This was followed by a $2-\mathrm{min}$ observation period. Total bout length was thus $10 \mathrm{~min}$.

In the nonshock round-robin, the mice were paired as above except that no shocks were given and bout length was extended to $20 \mathrm{~min}$. Following the method of Clark \& Schein (1966), dominance in a given bout was estimated by degree of control exercised by one animal over the other.

\section{RESULTS}

A variety of agonistic acts were observed in the shock period of the foot-shock round-robin. Pre- and postshock periods were characterized by nonagonistic grooming and scanning, and occasional sniffing or nosing of possible agonistic nature. In the shock period one serious methodological difficulty involved the identification of an animal performing a particular postural reaction or act. In most cases, this was virtually impossible to do. This being the case, only the total frequency of simultaneous upright posturing by both animals upon shock delivery is analyzed in this study. Bout totals of these simultaneous upright reactions ranged from $0-49$.

In the nonshock round-robin, attention was focused upon the identity of an animal performing a given act so that a judgment as to the dominant animal in that bout could be made. As mentioned earlier, these judgments were made on the basis of degree of control exercised by one animal over the other. For example, if one animal frequently aggressively groomed the other, or if nosing, sniffing, or touching resulted in withdrawal by the other animal, the animal doing the grooming, nosing, etc., would be judged dominant and the opponent submissive. It might be pointed out that no full-blown fights or attacks were observed. An animal was assigned a rank in the dominance hierarchy ( 5 being most dominant) on the basis of the total number of bouts in which he was judged dominant.

Figure 1 presents the sum of upright reactions for each animal's four shock round-robin bouts as a function of dominance rank as determined in the nonshock round-robin.

Bout totals of upright reactions in the shock round-robin varied considerably $(0-49)$. The dominance rank obtained in the nonshock round-robin can be used to analyze the upright reaction data in a bout-by-bout fashion. Figure 2 presents each animal's four bout totals plotted as a function of his rank $\left(R_{j}\right)$ minus his opponent's rank $\left(\mathbf{R}_{\mathbf{j}}\right)$.

From this it can be seen that the observed frequency of upright reactions appears to be a function of the position in the dominance hierarchy and difference in position as conveniently expressed by $\mathbf{R}_{\mathbf{i}}-\mathbf{R}_{\mathbf{j}}$.

$$
\text { DISCUSSION }
$$

The results seem clearly to indicate a positive relationship between dominance rank and frequency of upright reactions observed in the foot-shock situation. The 


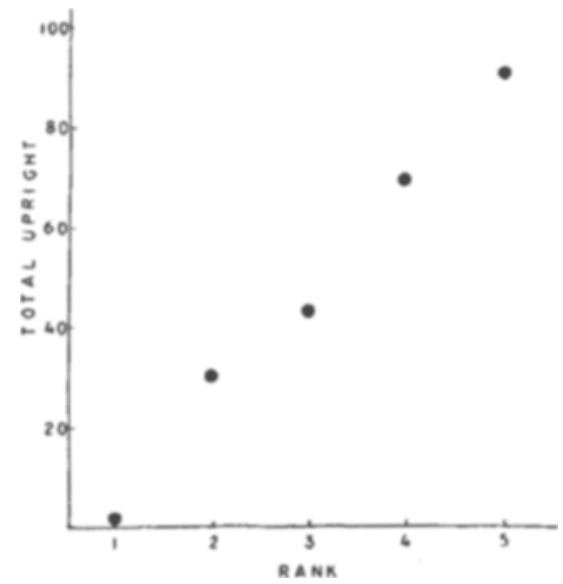

Fig. 1. Total upright reactions (summed over four bouts) plotted as a function of dominance rank.

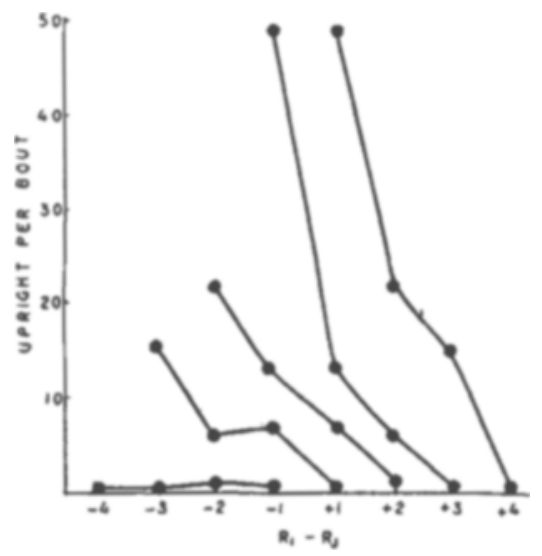

Fig. 2. Bout-by-bout analysis of upright reactions as a function of dominance rank (R) as expressed by difference in rank $\left(\mathbf{R}_{\mathbf{i}}-\mathbf{R}_{\mathbf{j}}\right)$.

role of experience in the development of this dominance hierarchy cannot, of course, be determined from this brief study. The results are valuable, however, in suggesting the true nature or meaning (i.e., proper classification) of the upright posturing observed in foot-shock situations.

As mentioned earlier, Grant \& McKin tosh (1963) classified the upright posture as an ambivalent posture, thereby stressing the control of this posture by simultaneously aroused but incompatible flight and attack "tendencies" or "drives." If we accept this for the moment (without getting sidetracked about what we mean by "tendencies" or "drives"), some degree of sense about the upright posture in the foot-shock situation begins to emerge. The shocks control the probability of flight, but complete flight (escape) from the shocks is precluded by the apparatus itself. The presence of another animal may control flight, attack, investigatory behavior, etc. When shocks are paired with the presence of another animal, we might assume that flight and attack tendencies might predominate rather than investigatory, etc. Thus, when flight-attack are simultaneously aroused in reasonable balance (assuming flight tendencies due to shock are roughly equivalent in both animals), we would expect to observe more upright posturings when both animals have approximately the same degree of attack tenclency as they would be expected to have if high and close in the dominance hierarchy. Possibly the upright posture has a releasing effect on the agonistic behavior of the opponent. Likewise, when difference in rank is large, we might expect that a dominant animal is stimulated in the flight-attack fashion, but that a submissive animal is stimulated more in a flight fashion (summation of shock and flight stimulation produced ty the behavior of other animal).

This is consistent with traditional interpretations of similar ambivalent behaviors (threat behaviors) as being those which produce flight, or other agonistic behavior in the opponent (Verplanck, 1957). Perhaps actual full-blown fighting is rarely observed in the foot-shock situation due to continual shock-produced flight tendencies resulting in an attack inhibition even in dominant animals.

By choosing appropriate values of dominance, shock level, shock rate, escape opportunity, etc., it would seem theoretically possible to maintain the attack-flight balance (or to alter it as desired) for a specified length of time. Indeed, the data (Ulich \& Azrin, 1962) indicate just this.

To conclude, it appears that the upright reaction is best identified or classified as a defensive threat behavior, or, if the Grant \& McKintosh (1963) vocabulary is preferred, as an ambivalent behavior. The above analysis is admittedly speculative. What is needed is clata (and technique) to indepen. dently vary and assess flight and attack "tendencies" and to combine them in various degrees. This work is now in progress in the author's laboratory.

\section{REFERENCES}

BAUER, F. J. Genetic and experiential factors affecting social relations in male mice. Journa of Comparative \& Physiological Psychology. $1956,49,359.364$.

BEEMAN, $\mathrm{E}$. A. The effect of male hormone on aggressive behavior in mice. Physiological Zoology, 1947, 20, 373-405.

CLARK, L. H., \& SCHEIN, M. W. Activities associated with conflict behavior in mice. Animal Biehaviour, 1966, 14, 44-49.
GINSBURG, B. E., \& ALLEE, W. C. Some effects of conditioning on social dominance and subordination in inbred strains of mice. Physiological Zoology, 1942, 15, 485-506.

GRANT, E. C., \& McKINTOSH, J. H. A comparison of the social postures of some common laboratory rodents. Behaviour, 1963, 21, 246-259.

KAHN, M. W. The effects of severe defeat at various age levels on the aggressive behavior of mice. Journal of Genetic Psychology, 1951, 79, 117-130.

KIMBRELL, G. McA. "Fighting response": A definitional problem. Psychological Record, $1968,18,639-640$.

KING, J. A. Recent findings in the experimental analysis of aggression, introductory remarks. American Zoologist, $1966,6,628$.

SCOTT, J. P. Incomplete adjustment caused by frustration of untrained fighting mice. Joumal of Comparative Psychology, 1946, 39, 379-390.

SCOTT, J. P. Emotional behavior caused by conflict between weak stimulatory and weak inhibitory training. Journal of Comparative \& Physiological Psychology, 1947, 40, 275-282. SCOTT, J. P. Agonistic behavior of mice and rats A review. American Zoologist, 1966, 6, 683-701.

SCOTT, J. P., \& FREDERICSON, E. The causes of fighting in mice and rats. Physiological Zodogy, 1951, 24, 273-309.

SCOTT, J. P., \& MARSTON, M. Non-adaptive behavior resulting from a series of defeats in fighting mice. Journal of Abnormal \& Social Psychology, 1953, 48, 417.428.

TEDESCHI, R. E., TEDESCHI, D. H., MUCHA A., COOK, L., MATTIS, P. A., \& FELLOWS, E. J. Effects of various centrally acting drugs on. fighting behavior of mice. Joumal of Pharmacology \& Experimental Therapeutics, 1959 , 125, 28-34.

ULRICH, R. Pain as a cause of aggression. American Zoologist, 1966, 6, 643-662.

ULRICH, R., \& AZRIN, N. H. Reflexive fighting in response to aversive stimulation. Journal of the Experimental Analysis of Behavior, 1962, 5, 511-520.

VanABEELEN, J. H. F. Effects of genotype on mouse behavior. Animal Behaviour, 1966, 14 218-226.

VERPLANCK, W. S. A glossary of some terms used in the objective science of behavior. Psychological Review, 1957, 64, No.6, pt. 2 (Supplement).

WARNE, M. C. A time analysis of certain aspects of the behavior of small groups of caged mice. Journal of Comparative \& Physiological Psychology, 1947, 40, 371-387.

\section{NOTES}

1. This report is adapted from a portion of a dissertation presented to the graduate council of the University of Tennessee in partial fulfillment of the requirements for the $\mathrm{PhD}$ degree in Psychology. The author is grateful to $\mathrm{E}$. Furchtgott, W.S. Verplanck, W. H. Calhoun, and J. C. Howell, not only for assistance and guidance during the course of the research, but also for several pleasant and profitable years of association. Special thanks are due NSF Visiting Scientist U. Weidmann from The University, Leicester, England, for serving as an unofficial adviser during the course of the research.

2. Now at Denison University, Granville, Ohio. 